\title{
Balancing service inclusion for primary and secondary customers experiencing vulnerabilities
}

\author{
Henna M. Leino, Leila Hurmerinta and Birgitta Sandberg \\ Department of Marketing and International Business, Turku School of Economics at the University of Turku, Turku, Finland
}

\begin{abstract}
Purpose - Secondary customers often experience secondary vulnerabilities that manifest in family-centred transformative services as other- and self-related customer needs. Yet, a relational perspective on primary and secondary customers' needs is lacking. The study analyses secondary customers' needs and their relationship to primary customers' needs to enhance well-being in customer entities. The service inclusion lens is used to understand customers' experiences of vulnerability.

Design/methodology/approach - The study uses an exploratory approach. The data consists of ethnographic observations and interviews of elderly residents (primary customers), their family members (secondary customers) and nurses in two nursing homes.

Findings - Primary and secondary customers' needs are interrelated (or unrelated) in four ways: they are separate, congruent, intertwined or discrepant. The vulnerability experiences fluctuate in intensity and over time, individually reflecting on these need dimensions.

Research limitations/implications - The study contributes to service research concerning customers' experiences of vulnerability, secondary customers and their inclusion in services. Primary customers' service inclusion may increase/decrease secondary customers' service inclusion and their experience of vulnerability. Moreover, secondary customers' inclusion is often necessary to foster primary customers' inclusion and well-being.

Practical implications - Fostering service inclusion and well-being for primary and secondary customers requires balanced inclusion and acknowledging the needs of both groups. Service providers may need to act as moderators within customer entities if discrepant needs occur.

Originality/value - The study addresses the under-researched areas of family members' customer needs, their relation to primary customers' needs, experiences of secondary vulnerability and context-related vulnerability.
\end{abstract}

Keywords Customer service, Well-being, Transformative, Secondary customer, Vulnerabilities, Customer needs, TSR, Nursing home, Service inclusion

Paper type Research paper

\section{Introduction}

It's so lovely to come here. You get care for yourself, too. Originally, I thought I'm only a next-of-kin, that there's no need for them to comfort me. But when you call here and the nurse says, 'Don't you worry 'bout a thing, you come when you can, everything's fine here.' And it's like [...] mercy. (Family member of a nursing home resident)

As this quote indicates, the influence potential of some services considerably extends beyond the primary customer, most often to family members. The primary customers of elderly care services are the elderly, who can be regarded as customers experiencing vulnerabilities. When the primary customer faces vulnerabilities, family members usually take on caregiver roles, and they can experience secondary vulnerability (Pavia and Mason, 2014), which is different from the vulnerability experienced by the primary customer but directly related to it. Often, family members are also closely involved and in supportive roles with regard to the service. Consequently, and based on their potential experience of secondary vulnerability, they can be regarded as secondary customers of these services (Leino, 2017).

The current issue and full text archive of this journal is available on Emerald Insight at: https://www.emerald.com/insight/0887-6045.htm

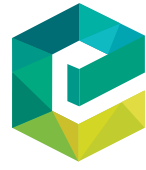

Journal of Services Marketing

35/6 (2021) 692-705

Emerald Publishing Limited [ISSN 0887-6045]

[DOI 10.1108/JSM-07-2020-0305]
Family members often make decisions on behalf of or together with the primary customer - typically due to the primary customer's bounded abilities - and they consider themselves and the person being cared for as a unit (Sarvimäki et al., 2017). Johns and Davey (2019) introduce the concept of the transformative service mediator (TSM) to explain how multiple actors (from service providers to consumer advocates, such as family members) can mediate services and value outcomes for consumers experiencing vulnerabilities. Besides mediating services for the primary customer, secondary customers are also influenced by the service provided to their

(C) Henna M. Leino, Leila Hurmerinta and Birgitta Sandberg. Published by Emerald Publishing Limited. This article is published under the Creative Commons Attribution (CC BY 4.0) licence. Anyone may reproduce, distribute, translate and create derivative works of this article (for both commercial and non-commercial purposes), subject to full attribution to the original publication and authors. The full terms of this licence maybe seen at http://creativecommons.org/licences/by/4.0/legalcode

The authors are grateful to the Emil Aaltonen Foundation for providing a project grant that supported this research. In addition, Henna M. Leino thanks the Foundation for Economic Education for the personal grant that supported advancing the paper. In addition, the authors wish to thank the special issue editors and anonymous reviewers for their insightful comments and recommendations, which allowed us to improve the article.

Received 28 July 2020

Revised 19 January 2021

23 April 2021

26 May 2021

Accepted 7 June 2021 
close other (Leino, 2017). Furthermore, individuals that experience secondary vulnerability may seek relief from systems and services originally designed for the primary customers facing vulnerabilities (Pavia and Mason, 2014). Thus, secondary customers also have special needs relating to these services, presumably other- and self-related. This may cause challenges if the services are not prepared to acknowledge both primary and secondary customers' needs and hence, service inclusion (Fisk et al., 2018) is not adequately fostered.

Transformative service research (TSR) advocates for value creation and well-being generation for the entire family (Anderson et al., 2013; Rosenbaum et al., 2011) or customer entity (Anderson et al., 2018). Family-centred care and family systems thinking are recommended, yet not systematic (Byrne, 2016; Fogarty and Mauksch, 2017). In health services such as hospice care, support for family caregivers is considered central, but studies and assessment tools typically concentrate on patients' rather than family caregivers' needs (Hudson et al., 2010). Family members' needs are understudied, especially in long-term care service environments (Garity, 2006), and more family-friendly practices should be developed, inclusive of the needs of the family (Bauer, 2007). This suggests that while family members may have access to services as companions of primary customers, their needs often remain undiscovered and/or unmet by the service provider.

Moreover, the COVID-19 pandemic has concretely highlighted how access to services and access to the customers within services is not self-evident. In particular, some individuals experiencing vulnerabilities have suffered from the pandemic and from service exclusion (Finsterwalder et al., 2020). The inclusion or exclusion of family members of customers who are experiencing vulnerabilities is not explicitly addressed in the emergent service inclusion theory from the TSR paradigm, which Fisk et al. (2018, p. 835) conceptualise as "an egalitarian system that provides customers [...] with fair access to a service, fair treatment during a service and fair opportunity to exit a service". Using service inclusion theory, Bianchi (2021) does study family members' role in assisting and thus enhancing elderly individuals' service inclusion, but the family members' experiences of vulnerability or their service exclusion are not addressed. Furthermore, Finsterwalder and Kuppelwieser (2020) call for clarity in the academic debate concerning the effects of transformative services beyond the focal actors involved.

Therefore, we use service inclusion as a lens through which to understand primary and secondary customers' experiences of vulnerability. The purpose herein is to study secondary customers' needs and their relationship to primary customers' needs in a nursing home service context. This is an essential context because the ageing population is a global phenomenon, and the number of elderly people who require caretaking is rapidly rising (Fisk et al., 2018; United Nations, 2017). Consequently, there is a high number of family members involved. We answer the following research questions: What kinds of needs do secondary customers have in a nursing home service environment? How do these needs relate to primary customers' needs? How do they reflect vulnerabilities?

The study addresses extended experiences of vulnerability within a family, responding to the call to study different layers of vulnerability (Luna, 2019; Pavia and Mason, 2014). This brings a novel perspective to the service inclusion discussion since the expanded understanding of relational customer needs and experienced vulnerabilities provides insights into how service inclusion, as a concept, relates to secondary customers. The study advocates for service inclusion for all members of a customer entity, but also introduces possible complexities arising from such inclusion. This responds to Kuppelwieser and Klaus' (2020) call to build more awareness of the inclusion challenge for the service marketing discipline. Thus, the study contributes to three specific, partially intertwined areas in the service theory and literature:

1 consumers who experience vulnerability;

2 secondary customers within services; and

3 service inclusion.

\section{Customers' multi-layered experiences of vulnerability in transformative services}

TSR advocates for research that studies how services can enhance the well-being of individuals and their families or community collectives (Anderson et al., 2013; Rosenbaum et al., 2011). To generate well-being, the service provider must recognise and meet customers' needs, including their latent needs (Hurmerinta and Sandberg, 2015). Research has been called for, especially on the omitted area of how service design and processes influence consumers experiencing vulnerabilities (Anderson et al., 2018; Rosenbaum et al., 2017). A focussed design for service inclusion is needed because service systems have a crucial role in promoting human well-being and because consumers who experience vulnerability often suffer from service exclusion (Fisk et al., 2018, 2020).

Fisk et al. (2018) suggest four pillars of service inclusion: enabling opportunities (providing access to services and the ability to receive and co-create valued services), offering choice (between different service offerings and opting out of services), relieving suffering (fair access to essential services that fulfil basic human needs) and fostering happiness (hedonic well-being from services) (p. 844). To understand how the pillars of service inclusion relate to the different layers of customers' vulnerability experiences, it is essential to first discuss vulnerability in general and in the customer context.

Vulnerability has been defined by the factors causing it, by its durability and by the sphere of influence. Universal human vulnerability (Rogers et al., 2012) or ordinary vulnerability (Sellman, 2005) refers to the paradigm that considers all human life as characterised by vulnerability, based on human embodiment, sociality and dependency on others. Contextual vulnerability refers to a relative and context-specific condition that may be faced by anyone in any situation (Baker et al., 2005; Luna, 2019; Shultz and Holbrook, 2009). These definitions imply that all of us can experience vulnerability, thus suggesting that issues such as service exclusion or service failing to meet our essential needs can generate feelings of vulnerability.

However, there are also specific factors that can exacerbate the experiences of vulnerability of some individuals or trigger experiences of extraordinary vulnerability (Rogers et al., 2012; Sellman, 2005). Often, this kind of vulnerability experience results from the presence of an underlying condition, such as health-related or capability-related challenge resulting from deficits in cognitive, biological and physiological abilities (Griffiths and Harmon, 2011; Hare et al., 2013), and from 
depending on others for care (Sellman, 2005). Thus, it typically concerns primary customers of healthcare or nursing services.

Dependency also generates experiences of vulnerability through another mechanism; due to the dependencies involved in human relationships, vulnerability is extended to close others (Mackenzie et al., 2014). This supports the concept of secondary vulnerability (Pavia and Mason, 2014) which is a relevant concept when considering the experiences of vulnerability and the service outcomes for the entire customer entity.

Experiences of secondary vulnerability or dependencies within a customer entity have been labelled with various parallel concepts in recent service research. Fletcher-Brown et al. (2020) introduce principal vulnerable consumers who are directly affected by the chronic disease and associate vulnerable consumers who have some proximity to the disease, for instance, by family or friendship connection. Associate vulnerable consumers act in consumer-producer roles, which highlights their active and co-creative roles even outside the service settings. Kelleher et al. (2020) label family caregivers as nonreferent beneficiaries who coordinate value co-creation in service systems on behalf of dependent family members (labelled as referent beneficiaries), thus describing their active role in service systems. Similarly, Johns and Davey's (2019) TSM concept implies an active role, as it explains how other actors mediate the services and their value outcomes for consumers experiencing vulnerabilities. These actors can range from service providers to consumer advocates, service gatekeepers and risk analysts, encompassing unofficial and official actors related to the consumer; thus, all TSMs are not in close relations with the consumer. Leino (2017) focuses on those actors who can be regarded as close others of the vulnerable customers and calls them secondary customers. She underscores their role as service recipients alongside the primary customers: 'secondary customers should be seen as an integral part of the service process [...] created to serve both the primary and secondary customers, yet recognising and addressing their differing needs in the service design.' (Leino, 2017, p. 766)

The concept of a secondary customer is adopted in this paper because the purpose is to specifically acknowledge the customer status of the family members, hence underscoring their needs as service recipients. The construct "customers' experiences of vulnerability" is used to refer to the customers' own experiences of vulnerability, but also to vulnerability experiences as observed by others, because some individuals "do not have the full range of capacities necessary to articulate the subjective experience of vulnerability", for instance infants or those with Alzheimer's disease (Sellman, 2005, p. 7).

\section{Nursing homes as a service and research context}

Besides the ageing population, the nursing home context is important due to the research gaps concerning family members. There is a shortage of research, especially on familycaregiver adjustment and family-caregiving roles in nursing home environments (Davies and Nolan, 2006; Garity, 2006). Moreover, this service context is sensitive and prone to triggering experiences of vulnerability, as it often evokes strong, even ambivalent emotions, such as guilt and relief in family members (Alonso et al., 2017; Paun et al., 2015).

Pavia and Mason (2014) propose that experiences of secondary vulnerability are emphasised in contexts where experiences of primary vulnerability result from complex, dynamic and unresolvable situations, meaning that the situation leading to experienced vulnerability cannot be remediated and the challenges leading to it are changing and ongoing. This applies to many transformative service contexts, nursing homes being among those, because the elderly need to move to the nursing home due to the unresolvable challenge of not coping independently and typically of the changing and ongoing decline in cognitive and/or physiological conditions. Furthermore, Sellman (2005) notes that to be in need of nursing, automatically means experiencing extraordinary vulnerability, due to feelings of dependency on others. In addition, nursing homes share certain features, such as the care being permanent and terminal, which may trigger experiences of vulnerabilities in both primary and secondary customers.

The family members' involvement in care has also been considered influential regarding primary customers' well-being (Backhaus et al., 2020; Reid and Chappell, 2017; Verbeek, 2017), but challenges in establishing partnerships between staff and family members are common (Verbeek, 2017). Bianchi (2021) argues that family members have a vital role in value cocreation and well-being for elderly consumers when they assist them in service inclusion by acting as TSMs (Johns and Davey, 2019). This implies that family members' (secondary customers') successful service inclusion may be an element that needs to be added to the service inclusion theory concerning primary customers who are experiencing vulnerability. Thus, family members' needs should be profoundly understood. The staff-family member relationship has been studied (Bauer, 2007) and individualised practices in family involvement have been recommended (Reid and Chappell, 2017), but the family members' personal customer needs and their relation to the residents' (primary customers') needs lack specific research. We address this gap in research.

\section{Methods}

We conducted an explorative, qualitative study in two private nursing homes. Pearl (pseudonymised) was established in the 2010s and Diamond (pseudonymised) was established in the 1990s. Pearl had 12 residents and Diamond had 48 residents. Each resident had a single room with bathroom facilities. The nursing homes offered a home-like environment - shared spaces with kitchen, dining space and a TV corner with sofas.

To engage customer needs in this context, we adopted multiple perspectives and qualitative methods for data collection (triangulation). This study used views on customers' needs from three perspectives: family members, residents and nurses (Figure 1).

All three perspectives were required to gain an accurate picture of the research phenomenon. Nurses served as validators and offered external clarifying views when residents were not able to properly express themselves, also sharing their experiences concerning family members' and residents' needs; these views were especially valuable for perceiving and interpreting latent needs. Due to the subject sensitivity and 
Figure 1 Contextual framework of the study

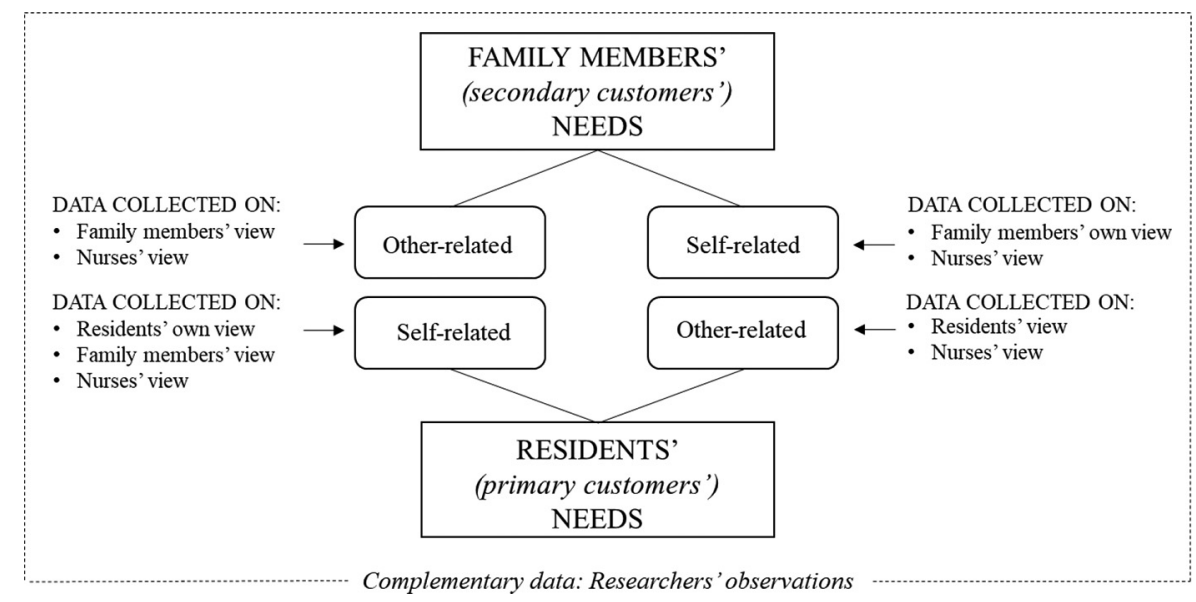

individuals' potential experiences of vulnerability, an ethical statement from our university's Research Ethics Committee was included.

All parties were informed about the study and assured of confidentiality. Participation was voluntary, and withdrawal was allowed without consequences. A signed informed consent to interview was acquired from residents and their family members; the latter on the part of residents who had impaired decision-making capacities. Residents' willingness for interviews was always ensured (Israel and Hay, 2006).

The data was gathered through interviews in everyday social settings at the nursing homes during two sequential periods: in 2014 at Pearl and in 2018 at Diamond. In addition, observing, interacting and living the phenomena within the nursing homes generated data (Figure 1), as the study included ethnographical features (Berg and Lune, 2004). After analysing the data collected at Pearl from different viewpoints, it seemed important to complement the data and validate the results by also collecting data in another nursing home, Diamond. Prolonged time in the field and gaining tacit knowledge on the cultural codes of the nursing home context, without a strictly structured scheme for observation, increased the rigour of the study by enabling us to extract the essential issues (such as relationships, interactions and latent needs) and centralise them in our analysis (von Koskull, 2020).

The interviews of residents and family members were based on predetermined themes stemming from the theoretical background - nursing home conceptions, and service expectations and experiences. The length of the resident interviews was $40 \mathrm{~min}$ on average, taking into account the residents' condition. Interviews of family members (like spouses and children) lasted from one to two hours. Fifteen residents and 29 family members were interviewed (Table 1). The low number of residents was due to memory disorders, which often made interviews impossible.

The nurses' interviews were also based on predetermined themes (expectations and needs of residents and families, roles and relationships, co-operation with customers). Altogether, 24 nurses were interviewed during their working hours. This led to a significant variation in interview length ( $15 \mathrm{~min}$ to $2 \mathrm{~h}$ ).

Altogether, the researchers spent 12 days systematically collecting observation data (Table 1) that focussed on daily life and behaviour, interactions and discussions that took place between residents, family members and nurses. The prolonged time for data collection enabled the observation of issues that would otherwise have gone unnoticed; the time spent on site also fostered informants' trust towards researchers. Informal, daily discussions with residents and their family members fundamentally advanced our understanding of primary and secondary customers' needs. Experiences of vulnerabilities are challenging to study explicitly and unequivocally, but they were inductively interpreted during interviews and observations (Baker et al., 2005). The interpretation of needs also revealed experiences of vulnerabilities. In addition to what the interviewees said, it was revealing how they said it and what their emotional state was.

The data analysis initially began in the data-collection phase. The transcribed data was analysed in three phases. Researchers first read the transcripts to gain an overview of needs emerging from the data. Based on this review, a loose analysis frame was determined, which included self-related/other-related concepts and the source of the information (resident, family member,

Table 1 Data collection

\begin{tabular}{|c|c|c|c|c|}
\hline & \multicolumn{4}{|c|}{ Customer entity } \\
\hline & $\begin{array}{l}\text { Residents } \\
\text { (interviews) }\end{array}$ & $\begin{array}{l}\text { Family members } \\
\text { (interviews) }\end{array}$ & $\begin{array}{c}\text { Nurses } \\
\text { (interviews) }\end{array}$ & $\begin{array}{c}\text { Systematic } \\
\text { observation (in days) }\end{array}$ \\
\hline Pearl & 9 (7 h 1 min) & 12 (7 h $55 \mathrm{~min})$ & 13 (8h $48 \mathrm{~min})$ & 7 (by four researchers) \\
\hline Diamond & 6 (3 h $15 \mathrm{~min})$ & 17 (26h $30 \mathrm{~min})$ & 11 (15 h 25 min) & 5 (by two researchers) \\
\hline Total interviews and lengths/ days of observations & 15 (10 h 16 min) & 29 (34 h 25 min) & 24 (24 h 13 min) & 12 \\
\hline
\end{tabular}


nurse). The data was then imported into NVivo and coded according to these concepts. Inductive coding allowed novel interpretations and classifications to arise from the data. The aim was to find upper-level categories for single subcategories that could be integrated into abstract patterns that illustrated their dynamic relationships. This required several iteration cycles, wherein terms and codes based on the quotes were combined, discussed and conceptualised by the researchers
(Corley and Gioia, 2004; Gioia et al., 2013). Finally, a framework for the relationships between primary and secondary customers' self-related and other-related needs was created (Figure 2).

The tables in the Findings section highlight the information attained, with quotes to illustrate the logic of the analysis. The short narratives of pseudonymised customers and quotes integrated into the text aim to bring 'readers closer to the

Figure 2 Data structure

First-order concepts

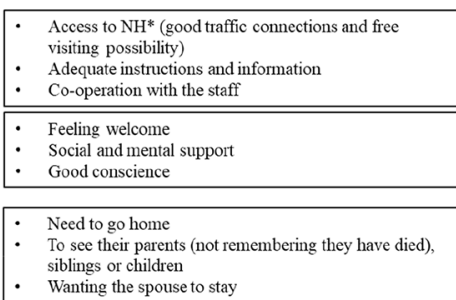

- Physiological needs (good food, hygiene)

- Safety and stability

\begin{tabular}{ll}
\hline - Unhurried encounters \\
Respectful interactions
\end{tabular}

- Having good and close relationships with the nurses

- Self-efficacy

Sense of freedom

Individual care

Maintaining sense of self

Maintaining old habits and routines

- Music, daytrips, other activities

- Company, social interactio

- Pleasant, home-like facilities and surroundings

Kind, friendly encounters with nurses

Unhurried encounters

(including nurses, other residents and other family members)

Recident's safety and transfer of responcibility to the $\mathrm{NH}$ brings relief and peace of mind for family member Trust in resident's good care enables good conscience and better quality of life for family member

When resident is in good care family members can concentrate on non-resident-related issues when talking with each other

- Anxiety or ill-being of a resident makes the family

member restless and concerned

Contentment of a resident can create better memories

the last years, months or days for the family member

Active visits and lively social life of a resident brings

good conscience for the family member

good conscience for the family member
Residents' will to live and meaningfulness brings joy and well-being for family members

- Knowing that (adult) children are well and safe brings peace of mind for resident

Resident's need to know that (adult) children can make right decisions in their everyday lives

Spouse's safety and well-being inportant

- Differing needs and/or opinions regarding clothing - Going outdoors vs. resting

Views on fumishing and decorating the resident's room

- Family members' presence at $\mathrm{NH}$ sometimes too intense Resident's best interests in family member's mind but based on false assumptions

- Questionable motives to visit Family member's visits vs. resident not desiring (long)

visits or discussions

Family member's non-visits vs. resident desiring visitor

Resident's best interests not in family member's mind when making decisions

Note: ${ }^{*} \mathrm{NH}=$ nursing home
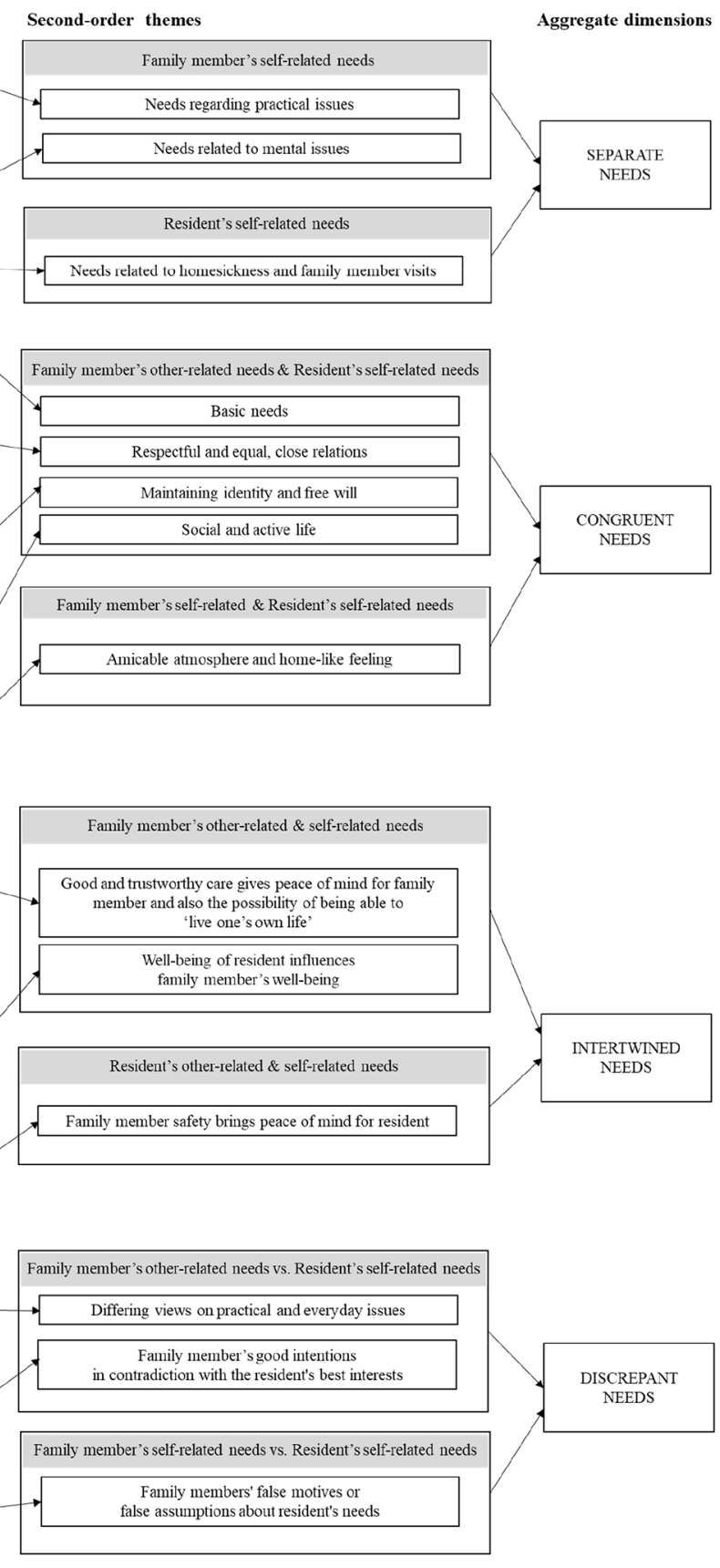
phenomenon' (Bansal and Corley, 2011, p. 235), to lead them to feel like they are in the nursing homes, sharing our interpretations.

\section{Findings}

Four dimensions of family members and residents' needs, and their relationship, arose from the data (Figure 2). Needs can be separate from each other (family members' and residents' needs are different) or congruent (a family member has a need of their own that is similar to the resident's need). They can also be intertwined: satisfying residents' needs also satisfies family members' needs (and vice versa) and/or generates well-being. Finally, needs can be discrepant: the family members' self- or other-related need contradicts the residents' self-related need.

These dimensions are presented in this section by introducing the themes behind them, exemplified by narratives and quotes. Each second-order theme is divided into subsections according to the 'owner' and type of need (otherrelated vs. self-related).

\subsection{Separate needs}

Marge visits her husband Paul nearly every day. She was a family caregiver for Paul for a long time and is still his devoted advocate. She wants as much information about his care and medication as possible and wishes to act in close co-operation with his nurses and doctor. She feels it is nice to visit the nursing home for the sake of daily social interaction, too. She would feel troubled if she did not frequently visit Paul. Attending peer-support groups makes her feel better.

Both residents and family members had service-related needs that were individual and separate from each other. Family members' needs consisted of needs regarding practical issues and needs relating to mental issues (Table 2). Regarding practical issues, it was important that family members had easy access to the nursing home. Receiving adequate and timely information and instructions was also important. Scarce possibilities to interact with the doctor were criticised and up-to-date healthrelated information was desired: 'I should be immediately informed of changes in medication, preferably beforehand' (Spouse). Instructions were needed in the admission phase regarding room furnishings and other practicalities. Co-production and co-operation with staff was important:
Here you can take part in care activities, such as assisting during meal times. And it's easy to talk with the nurses. The problematic issues can be solved together. (Spouse)

Needs related to mental issues consisted of feeling welcome, receiving social and mental support, and having a good conscience.

[It's] really nice to come here, you always feel very welcome and you can ask the nurses how things are, and they'll tell you with pleasure. They pay attention to you. (Adult child)

The evident need of family members for social and mental support was manifested as a need to share their worries with nurses or peer customers or to participate in a peer-support group. Support needs were very individual. Some considered the peer-support group vital, while others did not wish to discuss private matters with other residents' family members and benefitted more from private discussions with nurses. Many considered frequent visits important to have a good conscience: "It would actually feel more burdensome if I couldn't come.” (Spouse).

Residents' self-related needs were related to homesickness and family member visits (Table 2). The nurses also stated this as a predominant need among residents. On the other hand, those residents who had settled well and forgotten their old home instead missed being at the nursing home when they were elsewhere. Some residents felt a need to see their parents (not remembering they had died), siblings or children: 'Dad should visit more often' (Resident). Some residents wanted their spouse to stay longer.

\subsection{Congruent needs}

Matthew loves to sing and gain attention, but he also likes the nurses to spend time with him one-on-one. This is what his family wishes for him: for the nurses to cherish his personality, take time to encounter him as an individual and support his identity in spite of his memory disease. His son values the same treatment for himself: for the nurses to take time to listen to his concerns and interact with him in a warm, genuine manner.

There were two categories of congruent needs in the data: 1) family members' other-related needs were aligned with residents' self-related needs, and 2) both had similar selfrelated needs (Table 3). The first category consisted of basic needs, having respectful and equal, close relationships, maintaining identity and free will and having a social and active life. Basic needs concerned physiological needs, such as food and hygiene, and needs related to safety and stability: "Now I know everything's fine. She can't leave for anywhere; she gets food and drink, and she has company" (Adult child). Safety was also valued from the residents' point of view: 'Well, you must feel

Table 2 Data supporting interpretations of separate needs

\section{Family member's self-related needs Needs regarding practical issues}

Needs related to mental issues

\section{Resident's self-related needs} Needs related to homesickness and family member visits
'I wish it were easier to reach the doctor and discuss [my wife's] medication with her. I wish the doctor attended the annual care meetings.' (Spouse)

'[In the previous place], the nurses just sat by the computer. I really needed co-operation with them.' (Adult child)

'It's almost like coming home. You always get a friendly reception.' (Spouse)

'We give family members "permission to rest", because they may be completely exhausted as the resident moves here. Then they may say, "It's lovely you said I can go."' (Nurse)

'I only hope to see my own children as often as possible.' (Resident)

' "Gimme the hat, gimme the jacket, I'll rip it!" she yells, so I won't leave.' (Spouse) 
Table 3 Data supporting interpretations of congruent needs

\begin{tabular}{|c|c|}
\hline \multicolumn{2}{|c|}{ Family member's other-related and resident's self-related needs } \\
\hline \multirow[t]{3}{*}{ Basic needs } & 'The food is awfully good here. We always wait for mealtimes.' (Resident) \\
\hline & $\begin{array}{l}\text { 'Checking the diapers. We were angry [when] we noticed it was in the morning, and [that the next time was] not until the } \\
\text { evening.' (Adult child) }\end{array}$ \\
\hline & $\begin{array}{l}\text { '[Her] aggressive attitude changed because she now feels that she's safe and these people understand her and take care } \\
\text { of her.' (Adult child) }\end{array}$ \\
\hline \multirow{3}{*}{$\begin{array}{l}\text { Respectful and equal, close } \\
\text { relations }\end{array}$} & 'It's well arranged here [. . . ] there's no rush.' (Resident) \\
\hline & $\begin{array}{l}\text { 'It feels like the nurses are never in a hurry, and I know they are.' (Adult child) 'Here, the nurses understand she's not deaf; } \\
\text { she just doesn't remember.' (Adult child) }\end{array}$ \\
\hline & he has awfully good relations with the nurses, and it feels so good.' (Spouse) \\
\hline \multirow[t]{3}{*}{ Maintaining self and free will } & $\begin{array}{l}\text { 'It's better to be independent, not relying too much on others' help. Otherwise, one gets used to life in an institution.' } \\
\text { (Resident) }\end{array}$ \\
\hline & 'Just caretaking and nice activities [for my mum], not to feel like a prisoner.' (Adult child) \\
\hline & $\begin{array}{l}\text { '[Her] clothes must always be nice. Those issues just come through that are her personality. The risk in diagnosing is that } \\
\text { one is no longer a person, but a diagnosis.' (Adult child) }\end{array}$ \\
\hline \multirow[t]{2}{*}{ Social and active life } & 'She's always loved music and singing. Here they have those, which is important.' (Adult child) \\
\hline & $\begin{array}{l}\text { 'One-on-one time is also needed. It's not only about changing the diapers or washing and dressing up, but giving time.' } \\
\text { (Adult child) }\end{array}$ \\
\hline \multicolumn{2}{|c|}{ Family member's self-related and resident's self-related needs } \\
\hline \multirow[t]{2}{*}{$\begin{array}{l}\text { Amicable atmosphere and } \\
\text { home-like feeling }\end{array}$} & $\begin{array}{l}\text { 'There's one resident whose room looks like a living room, but with a bed: there's even a carpet. I think it's the most } \\
\text { home-like of these rooms.' (Nurse) }\end{array}$ \\
\hline & $\begin{array}{l}\text { 'I find it really nice that nurses know my mum by name. That makes me feel like I'm coming to mum's home.' (Adult child) } \\
\text { 'There's [a] sauna and barbequing. It's like living everyday life in a family.' (Adult child) }\end{array}$ \\
\hline
\end{tabular}

comfortable when the facilities here are so fine and it's safe' (Resident). The nurses and family members all considered routines and the stability of nurses to play a key role in creating safety and stability for residents:

Due to memory disease, there's anxiety and a need to have someone pampering and being close, assuring them everything's fine. And safety, to have the same faces around all the time. (Nurse)

Stability also referred to the possibility of residents staying at the nursing home for the rest of their lives:

They even have terminal care, [so] he can stay here 'til the end. It would be very confusing for him to change places and have different people around. (Spouse)

Having respectful and equal, close relations between nurses and residents was essential. This manifested as the need for unhurried encounters, respectful interactions and having good and close relationships with the nurses, referring to a humane presence and equality with residents:

They should have situational understanding. When going to my mother's room, [they should think], 'Is everything fine? She is Mrs. L., what's her thing?'; to pause and not just take care of some current issue. (Adult child)

A humane approach was also underscored by the hope for good and close relationships with the nurses: 'There are a couple of nurses who like my Mom very much, [which results in positive changes], although she may bang someone with a drinking glass' (Adult child). Moreover, close relations alleviated homesickness: 'I have awfully nice nurses, and it helps [with homesickness]. Some are particularly nice, even feel like next-of-kin' (Resident).

Maintaining identity and free will were valued: issues of selfefficacy, a sense of freedom, individual care and maintaining a sense of self and old habits and routines were emphasised. Selfefficacy and a sense of freedom were even connected to each other: 'A human being is more peaceful when there's something to do. To do the laundry, have a walk outside, not being in jail'
(Nurse). The resident's identity was supported by maintaining a sense of self: 'This is home-like, and people can wear their own clothes and be themselves' (Adult child); as well as by old habits and routines: 'She always has tea and toast, so it's no use offering her porridge' (Nurse). These were enabled by individual care:

It's great that she has 'my nurse', a person who knows her physical wellbeing and medical record; but also, who she is as a person: what she likes, what brings her delight. (Adult child)

Enjoying oneself through having a social and active life was also desired. Music, daytrips and other activities, as well as company and social interaction, were considered important, despite memory disorders:

She doesn't remember those moments, but in that very moment, she's enjoying [them]. And the things like daytrips, they cheer up a person's habitus. The way of life is very important. (Adult child)

The company of other people and social interaction were valued by residents: 'I don't always fancy being in my room; then I go to the club [the living room] to see who's there and to chat' (Resident). The importance of this was also recognised by this resident's family member: 'You can see the influence of her social environment. She's like a different person' (Adult child).

The second category of congruent needs (residents and family members having similar self-related needs) concerned the amicable atmosphere and home-like feeling of the nursing home, which resulted from pleasant, home-like facilities and surroundings, kind and friendly encounters with nurses, unhurried encounters and a social community (which included nurses, other residents and other family members). The social community of the nursing home was not only important for residents, but also for family members: 'It's nice to come here because of the community. The social life is covered when being here: discussions and humour, too' (Spouse). 


\subsection{Intertwined needs}

Mary was initially in another nursing home, which she aggressively resisted. After moving to the current place, she feels safe and comfortable, and she's more like her old self. Now, Mary's daughter, Heather, feels much more at ease and says she no longer feels constantly concerned. She values the individual care her mum receives and feels the nurses take full responsibility for her care; in the previous place, nurses asked family members what to do when they could not cope with residents. Mary's well-being is reflected in Heather's well-being, and vice versa. Visits from Mary's children are the high point of her week, and she feels peaceful when she knows they are fine.

The needs were intertwined in two ways:

1 family members' other-related needs were intertwined with their self-related needs, so fulfilling a resident's need simultaneously fulfilled a family member's need; and

2 residents' other-related needs were connected to their selfrelated needs (Table 4).

It was vital for family members to know that residents received good and trustworthy care, because it gave family members peace of mind and enabled them 'to also live their own life'. Family members needed to feel that residents were safe, and that the responsibility of care was transferred to the nurses. This was especially essential for those who had previously been the primary caregivers:

I feel relieved that she is safe and sound. I think she's happy at the moment, which makes me happy and calm because I don't need to worry in the middle of the night whether she'll call me in panic. The burden has been lifted off my shoulders. (Adult child)

Having trust in good care also allowed family members to have a good conscience, which affected their quality of life. In almost all cases, the well-being of the resident meant well-being for the family member. The anxiety or ill-being of a resident concerned the family members:

If it seems that something is not quite right, you think about it in the evening, too. So yes, it definitely has an influence [on my well-being]. (Spouse)

Residents' well-being not only influenced family members in the present moment, but also had long-term consequences, such as forming better memories:

It gives you a good feeling that she'll have a nice time 'til the end. It's maybe even possible to forget the lousier period of time [before moving into the nursing home]. (Adult child)
Family members often considered it important for residents to have visitors and a lively social life. Therefore, some family members frequently visited the resident to serve this need and to have a better conscience. Moreover, the residents' will to live and meaningfulness in their lives - for instance, enjoying a daytrip or visitors - brought joy and well-being for family members: 'She said, "Oh, how I wish to live long enough to see [my great-granddaughter] grow up.” For me that was a relief to hear' (Adult child).

The second category of intertwined needs concerned residents' other-related needs. Residents were concerned about their family members' safety and well-being and needed reassurance to attain peace of mind: 'If she's had a sad day, she's also asked whether we children are safe. A mother is always a mother' (Adult child).

\subsection{Discrepant needs}

Richard felt guilty when his wife, Rose, needed to move to a nursing home. He wanted to see how the nurses cared for her and to be involved in decisions concerning her care, even staying overnight. Richard takes Rose out daily for fresh air. He cares for her best by actively participating in caregiving, but the nurses say it can be difficult to get to know a resident if the family member is constantly present. Moreover, the nurses noticed that Rose sometimes needed rest instead of going out. They also see that Richard is exhausted after intense caregiving and wish to also consider his well-being, so they convince him to take more time for himself. It is difficult at first, but afterwards, Richard is satisfied when given 'permission' to stay home every once in a while.

The discrepant needs of residents and family members seemed to cause misunderstandings that placed the nurses in a difficult position. These discrepancies occurred between family members' other-related and residents' self-related needs, as well as between family members' and residents' self-related needs (Table 5). Family members' other-related needs differed from residents' self-related needs regarding practical and everyday issues, such as clothing, going outdoors and furnishing/ decorating the resident's room: 'Maybe she would've wanted flower curtains, but I didn't. I thought a light colour [was better] suited, so I hung them before she came here' (Adult child).

Table 4 Data supporting interpretations of intertwined needs

Family member's other-related and self-related needs Good and trustworthy care $=>$ Peace of mind for family member and possibility to 'also live one's own life'

Well-being of resident $=>$ Well-being for family member

Resident's other-related and self-related needs Family member safety $=>$ Peace of mind for resident
'In the beginning, I was constantly thinking about Mum, but not anymore. When I exit that door, I can live my own life.' (Adult child)

'The interaction between me and other family members was very much related to [Mum], to Alzheimer's and home care. Now it's different.' (Adult child)

'If he were in a place that wasn't good for him, I'd be distressed all the time.' (Adult child) 'For the next-of-kin, it's most important that their close other is feeling well.' (Nurse)

'Just that [my] children remain healthy - that's the best thing.' (Resident) 'You don't need to come along this time [on a trip]; our girls will be fine, [and] you can just rest.' (Adult child)

'She leaves the telly and radio on for [her late spouse] and says she'll have a meal now, [and it] won't be long. She takes care.' (Nurse) 
Table 5 Data supporting interpretations of discrepant needs

Family member's other-related vs. resident's self-related needs

Differing views on practical and everyday issues

'His daughter-in-law kept saying he's never worn short underpants. Now that she finally brought them, the resident is very happy.' (Nurse)

'Some next-of-kin don't realise how unwell a resident is, like [when they are] too tired to attend a daytrip. There may be suspicion towards us for why we didn't go.' (Nurse)

'He thinks he's not here to stay. He probably thinks if [his hobby-related items] are brought here, the last chance [to go] back home is gone.' (Adult child)

Family members' good intentions do not always serve the 'What's ethically correct? Is it okay that she comes every day and the [resident] residents' best interests becomes sad every day [that] she doesn't take him with her?' (Nurse)

Family member's self-related needs vs. resident's self-related needs

Family members' false motives or false assumptions about 'We had a difficult consideration, as [her male friend] wants her home sometimes. [Her] residents' needs $=>$ Negative influence on resident

daughters worry whether she's being abused.' (Nurse)

'She's anxious if her sons visit. They've sometimes bummed money off her.' (Nurse) 'Mum clearly gets tired. She probably wonders, "Who is this? Maybe I know her".' (Adult child)

'It's a pity that some residents don't have next-of-kin, or they are not in touch. Mrs. E. started crying because she never has visitors.' (Nurse)
Discrepancies were also detected when family members' good intentions were in contradiction with the residents' best interests. The family member's presence at the nursing home was sometimes too intense, if it complicated the resident's settling-in process. This varied individually: the presence was good for some, and for others, it was not. Discrepant needs also appeared when a family member had a resident's best interests in mind based on false assumptions. For instance, family members brought framed photos, but residents with memory disorders often turned them face-down because they did not know who was in the photos, which was confusing. In some cases, the photos reminded them of the past, of things currently experienced as lost, which caused sadness.

A source of discrepancy between family members' and residents' self-related needs was the family members' false motives or false assumptions about the resident's needs, which negatively influenced the resident. These manifested as questionable motives to visit, such as asking for money, family member visits when the resident did not want visitors and family members not having the resident's best interests in mind when making decisions concerning them.

Each customer entity may contain all four dimensions of needs, but especially the discrepant needs often resulted either from family members' overly committed and detailed involvement in care or from the family members' ignorance of the primary customer's care and well-being.

\section{Discussion}

This section analyses the relationship between experienced vulnerability, customer needs and service inclusion. Building on the extant theory on vulnerability and on the findings from our study, it seems that universal human vulnerability has an overarching influence, as customers are emotionally affected and experience vulnerability regarding themselves and others, especially when depending on others for care. This can manifest, for instance, as fear and sorrow, thus further influencing their service needs. In a nursing home environment, dependency often occurs within the primary customer-secondary customer(s)-staff triad. This can generate context-related experiences of vulnerability, together with the care facilities and their boundaries, for both primary and secondary customers (e.g. due to a lack of self- efficacy or agency). For primary customers, the condition-based experience of vulnerability (e.g. illness or an inability to cope independently due to Alzheimer's disease) is typically the reason for becoming a care service customer, and this generates multiple service needs (e.g. regarding emotional and physical support). Since secondary customers' experiences of secondary vulnerability stem from the primary customer's experiences of vulnerability, they mostly manifest as other-related needs, such as concern over the primary customer's well-being, but also as self-related needs concerning, for instance, emotional support and the adequacy of information.

We illustrate these perceptions of customers' experienced vulnerabilities and their influence on the needs in Figure 3. In the middle of the figure, the primary and secondary customers' needs are depicted in relation to one another, as based on our findings: they can be separate, congruent, intertwined or discrepant. The figure does not, however, imply that needs are dictated by vulnerability experiences. It is also essential to note that experiences of vulnerability vary individually and over time. Hence, the same context can trigger experiences of vulnerability for some customers but not for others.

Next, primary and secondary customers' experienced vulnerabilities and relational needs will be discussed in light of the four pillars of service inclusion: enabling opportunities, offering choice, relieving suffering and fostering happiness (Fisk et al., 2018).

The primary customers' experiences of vulnerability stemming from deterioration in self-efficacy and a lack of selfdetermination were emphasised, especially during the first few weeks of adjustment. Homesickness and rebellion were typical manifestations of these experiences. Thus, in this context, access to the service caused experience of vulnerability for primary customers due to lack of choice (it was not possible to exit the service), even though service inclusion was pursued through fair treatment, as their suffering was relieved and even their happiness was fostered through good care and meaningful activities. In other words, meeting all of the primary customer's self-related needs was not possible, and complete service inclusion was challenging if the customer was reluctant to accept the service. If the adjustment was successful the well-being outcomes were positive for both primary and secondary customers and this seemed to alleviate the experiences of vulnerability. 
Figure 3 Relationship between primary and secondary customer's self- and other-related needs, influenced by experienced vulnerabilities

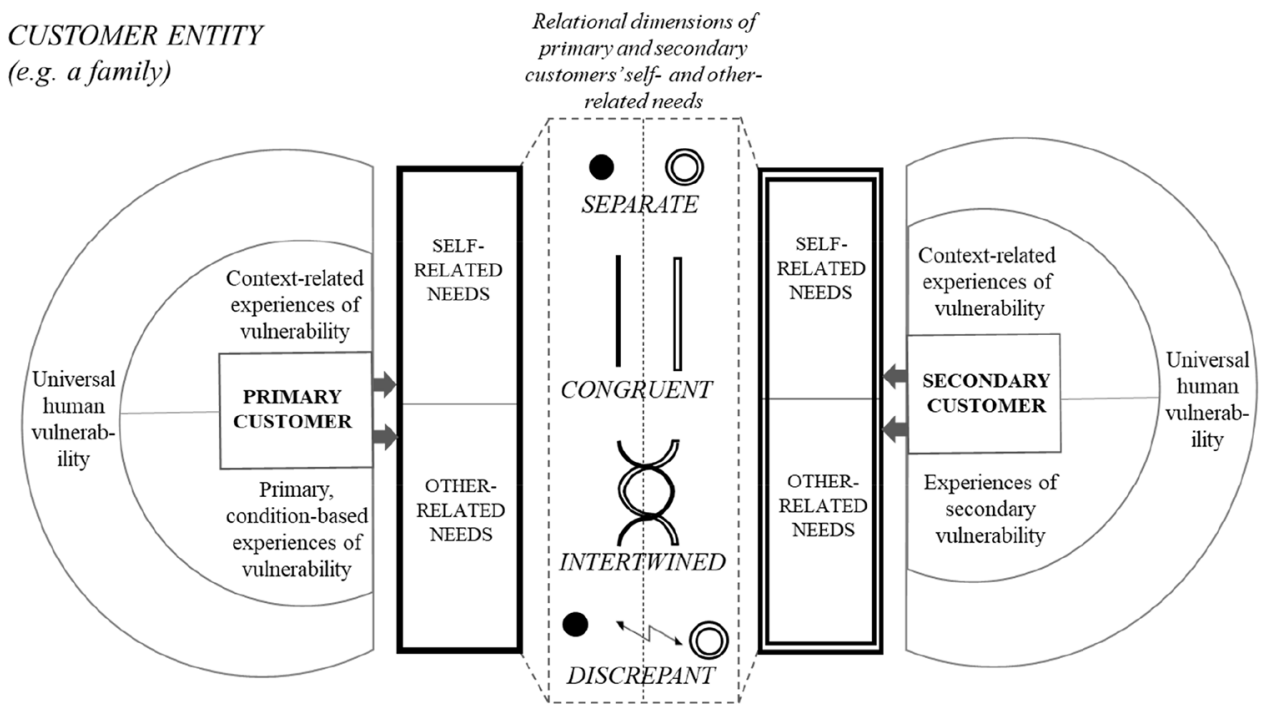

The secondary customers' experiences of secondary vulnerability appeared to result from issues such as them feeling guilty about moving their elderly relative into a nursing home or because they no longer had control over the care arrangements. Also, the life-changing transition phase, the resident's adjustment and changes in the relationship were confusing for family members. A latent need to receive guidance and support appeared, but often family members were not able to express the need explicitly. Also, concerns over the resident's wellbeing and uncertainty related to his/her future changes and end-of-life care seemed to trigger experiences of vulnerability and preoccupy family members. They manifested especially as needs concerning emotional support, trust in the care quality and adequate information concerning the resident's well-being. These aspects highlight the importance of secondary customers' service inclusion: enabling opportunities for them to be involved in the service, to receive support, and to gain access to information, and relieving their suffering (alleviating concerns) through creating trust in good care. Suffering is a strong word and refers to unmet basic needs in Fisk et al. (2018), but it is considered relevant in this context because constant otherrelated concerns cause mental suffering for family members.

Thus, services can increase or decrease the experienced vulnerability by meeting or not meeting customer needs. Vulnerabilities triggered in or by the service can also generate additional needs for both primary and secondary customers, such as support needs or even a need to exit the service. For instance, some residents had moved to Diamond because they did not adjust to their previous nursing home, which is an example of offering choice (to exit) for the primary customer, and consequently, for the secondary customer.

Due to the intertwined needs and well-being of primary and secondary customers, fostering happiness had a multiplier effect: providing meaningfulness and happy moments for primary customers also generated well-being and happiness for secondary customers. Moreover, the primary customers' happiness was often dependent on the secondary customers' visits, which indicates that the service inclusion of secondary customers was necessary to generate well-being for primary customers. Yet, in some cases, the impact was the opposite; if the primary and secondary customers' needs were discrepant, granting service inclusion for the secondary customer was potentially negative for the primary customer's well-being if it resulted in aggressive visits or excessive power of choice within the service setting.

Overall, this discussion generates insights for service inclusion theory (Fisk et al., 2018):

- it is challenging to ensure complete service inclusion for a reluctant customer;

- each of the service inclusion pillars is also pertinent for secondary customers' well-being, especially when they experience strong secondary vulnerability; and

- secondary customers' service inclusion is essential for the happiness and well-being of primary customers; without it, some pillars of service inclusion for primary customers may remain incomplete.

Yet, sometimes, although very rarely (in the case of false motives and malevolent behaviour), the inclusion of secondary customers may harm primary customers' well-being.

\section{Conclusions}

\subsection{Theoretical contributions}

The study provides theoretical contributions to the literature on secondary customers within services, consumers' experiences of vulnerability and service inclusion of primary and secondary customers.

First, the primary and secondary customers' needs are interrelated (or unrelated) in four ways: they are separate, congruent, intertwined or discrepant (Figure 3). Embodying the interrelatedness of needs in a customer entity, the study contributes to the service literature by supporting the adoption of an extended consumer/ customer view (Fletcher-Brown et al., 2020; Leino, 2017) and a relational perspective (Kelleher et al., 2020), and provides an understanding of customer needs, including latent ones. The family member viewpoint (Alonso et al., 2017; Verbeek, 2017) and 
patient/resident viewpoint (Griffiths and Harmon, 2011; Hare et al., 2013) have been studied separately, but a gap in using the relational perspective has existed.

Second, the context-specific factors of a service environment, such as the terminal, permanent, holistic and personal nature of the service, together with the liminal, life-changing phase that requires intense adaptation by primary and secondary customers, may exacerbate the experience of vulnerability. This reinforces Pavia and Mason's (2014) proposition that especially individuals experiencing vulnerability from a complex, dynamic and unresolvable situation expose their social network to experiencing secondary vulnerability. Thus, the findings from the nursing home context are transferable to other service contexts with these characteristics, such as palliative care, endof-life care, or understudied 'captive services' characterised by dependencies (Rayburn, 2015). Paradoxically, captiveness and permanence also created safety and decreased experiences of secondary vulnerability by alleviating family members' (especially adult children's) concerns.

Thus, third, the study contributes to service inclusion theory by suggesting that the service inclusion of primary customers may result in the service inclusion of secondary customers (or vice versa), but also in service exclusion if the needs of both are not acknowledged or if trade-offs are made between these actors' needs (McColl-Kennedy et al., 2020; Sandberg et al., 2021). We label the first phenomenon as supportive co-inclusion and the latter as counter-effective inclusion, as presented in Figure 4. Also, counter-effective exclusion is possible, meaning, for instance, that the exclusion of a secondary customer enhances the inclusion of the primary customer. The least desirable outcome is disruptive co-exclusion, referring to a situation where the unfair treatment of either the primary or secondary customer leads to the unfair treatment and exclusion of the other (e.g. if access to a service is denied from the primary customer, the secondary customer is also left without support from the service provider). These outcomes call for balanced inclusion of primary and secondary customers and warrant further research on the dimensions and meanings of service inclusion, especially in service contexts with 'reluctant customers' (McColl-Kennedy et al., 2015) and in contexts or exceptional situations where access is limited for secondary customers (cf. COVID-19 restrictions).

Fourth, due to the primary and secondary customers' intertwined needs, experienced vulnerability and well-being, we build on the bridge metaphor by Fisk et al. (2018, p. 845) and suggest that the total service inclusion of primary customers often requires secondary customers' service inclusion. This can be considered as the cables connecting all four pillars of service inclusion, and interacting with the deck of the bridge (i.e. the primary customers). This applies especially when secondary customers act as transformative service mediators (TSMs) for primary customers (cf. Johns and Davey, 2019). Bianchi (2021) argues that family members have an essential role in fostering elderly customers' service inclusion. We expand on that, and suggest that mutual support and cooperation between service providers and secondary customers enables transformative outcomes for both primary and secondary customers (excluding those rare cases when secondary customers do not promote the best interests of primary customers). This influence mechanism is presented in Figure 4 which illustrates how the service provider's/system's response can alleviate or exacerbate experiences of vulnerability and thus also influence well-being in a customer entity.

These insights add understanding to the service literature concerning customers who experience vulnerabilities and their close network, contributing to TSR's endeavours to understand consumers experiencing vulnerabilities in service settings (Rosenbaum et al., 2017). The findings contribute to TSR not only by suggesting how to improve the well-being of customers that experience vulnerabilities but also by suggesting how to relieve their suffering, which is an overlooked TSR outcome (Cheung and McColl-Kennedy, 2019; Nasr and Fisk, 2019). The explicit, relational perspective on family members' needs adds a novel angle to service inclusion theory (Fisk et al., 2018) by explaining some of the challenges faced by service inclusion goals. The theory implicitly assumes that a customer may be an entity, but it does not address the possible discrepancies that arise from a customer entity's individual members' service inclusion or from the variety of need dimensions within a customer entity.

Figure 4 Influence mechanism between primary and secondary customers' vulnerability experiences, relational needs and service inclusion

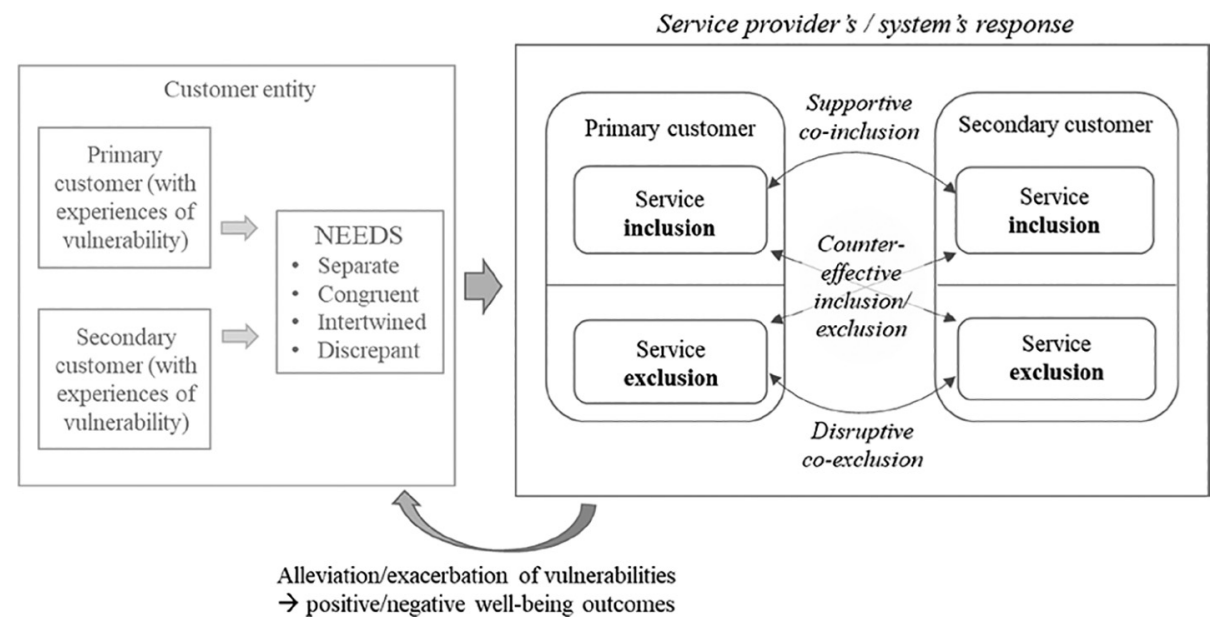




\subsection{Managerial implications}

Based on the findings, multilateral experiences of vulnerability and needs in a customer entity require careful recognition. This section suggests how service providers could address the relational needs to generate well-being for a customer entity. These implications apply in multiple transformative service contexts, but examples are provided from the nursing home context.

The findings advocate for the service inclusion of family members; their experiences of universal, context-related and secondary vulnerability and needs require service providers' attention alongside residents' needs. For instance, family members' separate, self-related needs may stem from guilt and experienced vulnerability that cause constant concern and suffering; professionals can alleviate this burden through proactive support and co-operation. The same measures also serve residents' separate, self-related needs, such as the alleviation of homesickness. For both primary and secondary customers, the congruent self- and other-related needs to engage in individual and respectful, friendly interaction and to maintain identity and free will were central needs, which calls for egalitarian and humane service systems (Fisk et al., 2018).

A critical point for the service inclusion discussion, however, are the intertwined and discrepant needs and the related wellbeing outcomes of primary and secondary customers. To provide family-centred care, the service provider needs to acknowledge the relationships and intertwined needs within a customer entity. This enables mutual benefits to be achieved through the service inclusion of the entire customer entity: secondary customers' inclusion may promote primary customers' well-being as such, but this will also assist the service provider in providing personalised and holistic care for the primary customer. Furthermore, this inclusion can generate transformative outcomes for the secondary customers themselves.

However, the discrepant needs revealed that even altruistic other-related needs and intentions of secondary customers may contradict primary customers' needs, possibly due to false assumptions or changing needs. When secondary customers act as service mediators for primary customers (Johns and Davey, 2019), the mediation can be harmful if they do not understand the primary customers' needs (Byrne, 2016). Thus, the service provider sometimes needs to act as a moderator between the primary and secondary customer, or between two or more secondary customers in a customer entity with differing opinions. Hence, while it is relevant to regard family members as customers, they should literally be seen as secondary so that their opinions do not overrule the primary customer's best interests.

In a context like a nursing home, experiences of vulnerability should not only be taken into account because of the primary customers' dependency and limited agency (Johns and Davey, 2019), but also cherished in order to fully convert the transformational potential of the service system into well-being outcomes, to support flourishing of individuals (Sellman, 2005). To achieve this, and to provide personal care, knowing customers as individuals is essential. Adequate resourcing and the stability of the staff foster this goal but are not a decisive solution if the latent and/or discrepant needs in a customer entity are not understood. In sum, the separate, congruent, intertwined and discrepant needs of primary and secondary customers should be addressed, and services orchestrated to generate transformative outcomes for both groups. The balanced inclusion of primary and secondary customers is needed when inclusive service systems are created.

\subsection{Limitations and further research}

The study has limitations regarding the residents' viewpoints. Due to severe memory disease, the interpretation of some residents' needs relied on observation and on nurses' and family members' views. Furthermore, the nursing homes in this study scored high in customer satisfaction surveys; places with lower standards could generate other findings, with an emphasis on different kinds of needs. Moreover, the intensity of vulnerability experience was not studied; therefore, the interpretations of the interrelations between customers' experienced vulnerability and needs are heuristic.

Since the recognition of customers' latent needs and the stability of the staff were found to be important, the educational needs and measures to support staff well-being are relevant future research topics. Further empirical exploration is also needed on secondary customers' experiences of service exclusion and on the impacts of this phenomenon, especially if a parent (with a physical or mental illness) is the primary customer and a minor is the secondary customer. The suggested need dimensions (Figure 3) are transferable, especially to other family-centred contexts, such as social services and disability services. Applicability to other contexts is relevant when the service involves a customer entity with multiple individuals.

\section{References}

Alonso, M.S., Prieto Ursúa, M. and Caperos, J.M. (2017), "The family caregiver after the institutionalization of the dependent elderly relative", Educational Gerontology, Vol. 43 No. 12, pp. 650-661.

Anderson, S., Nasr, L. and Rayburn, S.W. (2018), "Transformative service research and service design: synergistic effects in healthcare", The Service Industries fournal, Vol. 38 Nos 1/2, pp. 99-113.

Anderson, L., Ostrom, A.L., Corus, C., Fisk, R.P., Gallan, A. S., Giraldo, M., Mende, M., Mulder, M., Rayburn, S.W., Rosenbaum, M.S., Shirahada, K. and Williams, J.D. (2013), "Transformative service research: an agenda for the future", Fournal of Business Research, Vol. 66 No. 8, pp. 1203-1210.

Backhaus, R., Hoek, L.J., de Vries, E., van Haastregt, J.C., Hamers, J.P. and Verbeek, H. (2020), "Interventions to foster family inclusion in nursing homes for people with dementia: a systematic review", BMC Geriatrics, Vol. 20 No. 1, pp. 1-17.

Baker, S.M., Gentry, J.W. and Rittenburg, T.L. (2005), "Building understanding of the domain of consumer vulnerability", Fournal of Macromarketing, Vol. 25 No. 2, pp. 128-139.

Bansal, P. and Corley, K. (2011), "From the editors - the coming of age for qualitative research: embracing the diversity of qualitative methods", Academy of Management fournal, Vol. 54 No. 2, pp. 233-237. 
Bauer, M. (2007), "Staff-family relationships in nursing home care: a typology of challenging behaviours", International Fournal of Older People Nursing, Vol. 2 No. 3, pp. 213-218.

Berg, B.L. and Lune, H. (2004), Qualitative Research Methods for the Social Sciences, Pearson, London.

Bianchi, C. (2021), "Exploring how internet services can enhance elderly well-being", fournal of Services Marketing.

Byrne, G. (2016), "The patient in psychosocial context: person-centred versus family-centred care", in Fitzgerald, J. and Byrne, G.J. (Eds), Psychosocial Dimensions of Medicine, IP Communications, Victoria, pp. 19-28.

Cheung, L. and McColl-Kennedy, J.R. (2019), "Addressing vulnerability: what role does marketing play?", fournal of Services Marketing, Vol. 33 No. 6, pp. 660-670.

Corley, K.G. and Gioia, D.A. (2004), "Identity ambiguity and change in the wake of a corporate spin-off", Administrative Science Quarterly, Vol. 49 No. 2, pp. 173-208.

Davies, S. and Nolan, M. (2006), "Making it better'. selfperceived roles of family caregivers of older people living in care homes: a qualitative study", International fournal of Nursing Studies, Vol. 43 No. 3, p. 281.

Finsterwalder, J., Kabadayi, S., Fisk, R.P. and Boenigk, S. (2020), "Creating hospitable service systems for refugees during a pandemic: leveraging resources for service inclusion", Fournal of Service Theory and Practice, Vol. 31 No. 2, pp. 247-263.

Finsterwalder, J. and Kuppelwieser, V.G. (2020), "Intentionality and transformative services: wellbeing cocreation and spill-over effects", Fournal of Retailing and Consumer Services, Vol. 52, p. 101922.

Fisk, R.P., Alkire (Née Nasr), L., Anderson, L., Bowen, D.E., Gruber, T., Ostrom, A.L. and Patrício, L. (2020), "Elevating the human experience (HX) through service research collaborations: introducing ServCollab", fournal of Service Management, Vol. 31 No. 4, pp. 615-635.

Fisk, R.P., Dean, A.M., Alkire, L., Joubert, A., Previte, J., Robertson, N., et al. (2018), "Design for service inclusion: creating inclusive service systems by 2050 ", fournal of Service Management, Vol. 29 No. 5, pp. 834-858.

Fletcher-Brown, J., Turnbull, S., Viglia, G., Chen, T. and Pereira, V. (2020), "Vulnerable consumer engagement: how corporate social media can facilitate the replenishment of depleted resources", International Fournal of Research in Marketing, Vol. 38 No. 2, doi: 10.1016/j.ijresmar.2020.06.002.

Fogarty, C.T. and Mauksch, L.B. (2017), "Imagine a clinical world without family systems thinking", Families, Systems, and Health, Vol. 35 No. 4, pp. 395-398.

Garity, J. (2006), "Caring for a family member with alzheimer's disease: coping with caregiver burden post-nursing home placement", fournal of Gerontological Nursing, Vol. 32 No. 6, p. 39.

Gioia, D.A., Corley, K.G. and Hamilton, A.L. (2013), "Seeking qualitative rigor in inductive research: notes on the Gioia methodology", Organizational Research Methods, Vol. 16 No. 1, pp. 15-31.

Griffiths, M.A. and Harmon, T.R. (2011), "Aging consumer vulnerabilities influencing factors of acquiescence to informed consent", fournal of Consumer Affairs, Vol. 45 No. 3, pp. 445-466.

Hare, C., Law, J. and Brennan, C. (2013), "The vulnerable healthcare consumer: an interpretive synthesis of the patient experience literature", International fournal of Consumer Studies, Vol. 37 No. 3, pp. 299-311.

Hudson, P.L., Trauer, T., Graham, S., Grande, G., Ewing, G., Payne, S. et al. (2010), "A systematic review of instruments related to family caregivers of palliative care patients", Palliative Medicine, Vol. 24 No. 7, pp. 656-668.

Hurmerinta, L. and Sandberg, B. (2015), "Sadness bright as glass: the acceptance of emotionally sensitive radical innovation", fournal of Marketing Management, Vol. 31 Nos 9/10, pp. 918-939.

Israel, M. and Hay, I. (2006), Research Ethics for Social Scientists, SAGE, Thousand Oaks, CA.

Johns, R. and Davey, J. (2019), "Introducing the transformative service mediator: value creation with vulnerable consumers", Fournal of Services Marketing, Vol. 33 No. 1, pp. 5-15.

Kelleher, C., O'Loughlin, D., Gummerus, J. and Peñaloza, L. (2020), "Shifting arrays of a kaleidoscope: the orchestration of relational value cocreation in service systems", Fournal of Service Research, Vol. 23 No. 2, pp. 211-228.

Kuppelwieser, V.G. and Klaus, P. (2020), "Viewpoint: a primer for inclusive service marketing theory", fournal of Services Marketing, Vol. 34 No. 6, pp. 749-756.

Leino, H.M. (2017), "Secondary but significant: secondary customers' existence, vulnerability and needs in care services", fournal of Services Marketing, Vol. 31 No. 7, pp. 760-770.

Luna, F. (2019), "Identifying and evaluating layers of vulnerability: a way forward", Developing World Bioethics, Vol. 19 No. 2, pp. 86-95.

McColl-Kennedy, J.R., Cheung, L. and Coote, L.V. (2020), "Tensions and trade-offs in multi-actor service ecosystems", Fournal of Business Research, Vol. 121, pp. 655-666.

McColl-Kennedy, J.R., Gustafsson, A., Jaakkola, E., Klaus, P., Radnor, Z.J., Perks, H. and Friman, M. (2015), "Fresh perspectives on customer experience", Fournal of Services Marketing, Vol. 29 Nos. 6/7, pp. 430-435.

Mackenzie, C., Rogers, W. and Dodds, S. (2014), "Introduction: what is vulnerability and why does it matter for moral theory?", in Mackenzie, C., Rogers, R. and Dodds, S. (Eds), Vulnerability: New Essays in Ethics and Feminist Philosophy, Oxford University Press, Oxford, pp. 1-29.

Nasr, L. and Fisk, R.P. (2019), "The global refugee crisis: how can transformative service researchers help?", The Service Industries fournal, Vol. 39 Nos 9/10, pp. 684-700.

Paun, O., Farran, C.J., Fogg, L., Loukissa, D., Thomas, P.E. and Hoyem, R. (2015), "A chronic grief intervention for dementia family caregivers in long-term care", Western Fournal of Nursing Research, Vol. 37 No. 1, pp. 6-27.

Pavia, T.M. and Mason, M.J. (2014), "Vulnerability and physical, cognitive, and behavioral impairment: model extensions and open questions", fournal of Macromarketing, Vol. 34 No. 4, pp. 471-485.

Rayburn, S.W. (2015), “Consumers' captive service experiences: it's YOU and ME", The Service Industries Fournal, Vol. 35 Nos 15/16, pp. 806-825.

Reid, R.C. and Chappell, N.L. (2017), "Family involvement in nursing homes: are family caregivers getting what they want?", Fournal of Applied Gerontology, Vol. 36 No. 8, pp. 993-1015. 
Rogers, W., Mackenzie, C. and Dodds, S. (2012), "Why bioethics needs a concept of vulnerability", IFFAB: International Fournal of Feminist Approaches to Bioethics, Vol. 5 No. 2, pp. 11-38.

Rosenbaum, M., Corus, C., Ostrom, A., Anderson, L., Fisk, R., Gallan, A., et al. (2011), "Conceptualisation and aspirations of transformative service research", fournal of Research for Consumers, No. 19.

Rosenbaum, M.S., Seger-Guttmann, T. and Giraldo, M. (2017), "Commentary: vulnerable consumers in service settings", fournal of Services Marketing, Vol. 31 No. 4/5, pp. 309-312.

Sandberg, B., Hurmerinta, L., Leino, H.M. and Menzfeld, M. (2021), "Autonomy or security? Core value trade-offs and spillovers in servicescapes for vulnerable customers", fournal of Service Research, p. 10946705211012472.

Sarvimäki, A., Stenbock-Hult, B., Sundell, E. and OeschBörman, C. (2017), "The vulnerability of family caregivers in relation to vulnerability as understood by nurses", Scandinavian fournal of Caring Sciences, Vol. 31 No. 1, pp. 112-119.
Sellman, D. (2005), "Towards an understanding of nursing as a response to human vulnerability", Nursing Philosophy, Vol. 6 No. 1, pp. 2-10.

Shultz, C.J. and Holbrook, M.B. (2009), "The paradoxical relationships between marketing and vulnerability", fournal of Public Policy \& Marketing, Vol. 28 No. 1, pp. 124-127.

United Nations (2017), "World population ageing 2017: highlights (ST/ESA/SER.A/397)", available at: www. un.org/en/development/desa/population/publications/pdf/ ageing/WPA2017_Highlights.pdf (accessed 11 July 2020).

Verbeek, H. (2017), "Inclusion and support of family members in nursing homes", Schüssler, S. and Lohrmann, C. (Eds), Dementia in Nursing Homes, Springer, Cham, pp. 67-76.

von Koskull, C. (2020), "Increasing rigor and relevance in service research through ethnography", Fournal of Services Marketing, Vol. 34 No. 1, pp. 74-77.

\section{Corresponding author}

Henna M. Leino can be contacted at: henna.leino@utu.fi 